\title{
Interaction Effects of the Host Country Image and Cultural Intelligence on Organizational Attractiveness in Emerging Economies"
}

\author{
Eunmi KIM ${ }^{1}$, Gahye HONG ${ }^{2}$ \\ 1 First Author Assistant Professor, Graduate School of International Studies, Pusan, Pusan National University \\ E-mail: eunmikim@pusan.ac.kr \\ 2 corresponding Author Research Professor, Korea University Business School, Seoul, Korea University \\ E-mail: gahyehong@korea.ac.kr
}

Received: February 15, 2020. Revised: March 3, 2020. Accepted: March 13, 2020.

\begin{abstract}
Purpose - The purpose of this paper is to advance the understanding of the relationship between host country image and cultural intelligence (CQ) on the attractiveness of expatriate destinations. Specifically, this study compares the different impacts of $\mathrm{CQ}$ on the relationship between host country image and subsidiary attractiveness by comparing a US-based subsidiary and a Vietnam-based one.

Research design and methodology - A total of 445 Korean full-time workers responded through an online survey. The survey randomly showed the participants one of two conditions for a potential expatriate location. The participants were asked to answer a series of questions on the organizational attractiveness of the subsidiaries from the perspective of an expatriate candidate and respond to a series of questions on individual CQ.

Results - Through a two-way ANOVA test, the results reveal that Korean expatriate candidates perceive that a Vietnam-based subsidiary is a less attractive destination for international assignment when compared to a USbased subsidiary. In addition, the positive moderating effect of cultural intelligence on the relationship between the host location and the subsidiary's attractiveness is stronger when Vietnam, rather than the US, is the assignment location.

Conclusions - Drawing upon AUM theory, this study confirmed that unfavorable country image affects subsidiaries' attractiveness for expatriate candidates, due to anxiety. However, this study showed the role of employees' CQ to mitigate these challenges. This study suggests providing information on positive conditions of expatriate locations and building systematic process for enhancing individual CQ for organizations.
\end{abstract}

Keywords: Country Image, Cultural Intelligence, Organizational Attractiveness, Emerging Economies, Expatriates

JEL Classification Code: M16, M31.

* This work was supported by a 2-Year Research Grant of Pusan National University. 


\section{Introduction}

Due to an increase and expansion of Multinational Enterprises (MNEs) in global markets, recruiting and selecting superior expatriates is pivotal to success. Expatriates refer to employees who are sent from a headquarters (HQs) to work and live in different host country for a certain period of time, ranging from one to several years (Caligiuri, 2000). By doing so, they can transfer the knowledge of the HQ into nationally dispersed subsidiaries and enhance control and coordination of host country nationals (Brewster et al., 2014). Accordingly, many MNEs are highly likely to dispatch superior expatriates to the various overseas subsidiaries (De Eccher \& Duarte, 2018). Despite the high demands of expatriates in the rise of globalization, potential expatriate candidates are generally reluctant to accept international mobility because it requires drastic changes in work and life (Dupuis et al., 2008; Harvey \& Moeller, 2009). Moreover, the failure rate of expatriates during international assignments are high (Pomeroy, 2006), which makes MNEs' more deliberate in their expatriate recruitment process.

Among the many barriers, location is one of the greatest to accept an international mobility (Dickmann et al., 2008; Dupuis et al., 2008; Froese et al., 2010; Hong \& Kim, 2019; Peltokorpi \& Froese, 2014). The expansion of MNEs into emerging economies is increasing tremendously due to oversaturated markets in developed economies (GMT, 2016). However, most of the prior expatriate literature has investigated international mobility choices among developed host countries (Baum \& Kabst, 2013; Shaffer et al., 2012). Moreover, recent surveys show that emerging economies are not regarded as a popular destination (GMT, 2016). This might be caused by the country image of emerging economies. Country image is one of the symbolic images that an individual may hold toward a certain country and it is mainly created through the economical, technological, and political developments of a given country (Martin \& Eroglu, 1993). Thus, it is possible that emerging countries have less favorable images for potential expatriates and this could affect to the attractiveness of the destination. Based on this analysis, the first purpose of this study is to investigate how the host country image of Vietnam can affect the subsidiary attractiveness for potential Korean expatriate candidates by comparing it with a US-based subsidiary.

Cultural intelligence has gained considerable attention in expatriate literature as it helps better understand intercultural interaction (Malek \& Budhwar, 2013). One of the common reasons that expatriates fail their foreign assignment is a lack of ability to adjust to the various circumstances in the host country during the overseas assignments (Pomeroy, 2006). Past research argues that individuals who have a high degree of cultural intelligence are more likely to act and adapt well to unfamiliar cultural situations, thus enhancing expatriate adjustment and performance (Ang et al., 2007; Earley, 2002; Malek \& Budhwar, 2013). Based on this assumption, the second purpose of this study is to suggest that cultural intelligence can potentially moderate the relationship between the host country image and subsidiary attractiveness. Specifically, we propose that the cultural intelligence of expatriate candidates may mitigate the effect of the less favored host country image of a Vietnam-based subsidiary on the subsidiary attractiveness compared to a US-based one.

This paper makes several considerable contributions to expatriate literature. First, this study suggests that the host country image serves as one of the obstacles for MNEs' subsidiaries in emerging countries in attracting talented expatriate applicants by comparing US and Vietnam-based subsidiaries among Korean expatriate candidates' expatriate subsidiaries. Thus, it advocates a better understanding of the effect of host country image on the intention of oversea assignments. Second, it applies anxiety/uncertainty management (AUM) theory in explaining the attractiveness of host locations (Black, 1988). Previously, there was a lack of theory explaining how potential expatriate applicants are attracted to the host location. However, by applying AUM theory, we clarify how both country image and cultural intelligence have an influence on the attractiveness of the host location for Korean expatriate candidates. Third, we identify individual cultural intelligence as an ability which might help mitigate a less favorable host country image on the attractiveness of international assignments. Considering the fact that it is hard to change the image of a host country and its subsequent effect on the subsidiary attractiveness, by employing staff who have a high level of cultural intelligence and are able to manage their anxiety and uncertainty related to their less favorable host location, such as is found in emerging economies, it will help international assignments succeed.

This paper is organized as follows. First, we present the theoretical framework and review the relevant literature which underpins the concepts of country image, cultural intelligence, and organizational attractiveness. Second, we develop hypotheses, and then samples are analyzed. Third, we report the key findings and the results are explained. Last, we provide conclusions, implications and limitations of this study. 


\section{Literature Review and Hypotheses Development}

\subsection{Literature Review}

\subsubsection{Organizational Attractiveness}

Organizational attractiveness refers to a potential applicants' willingness to pursue a job and accept job offers (Lievens et al., 2005). Managing organizational attractiveness has long been regarded as an important factor, as it is decisive in affecting potential applicants' actual job choice in the recruitment literature (Turban et al., 1998; Van Hoye \& Saks, 2011). It plays an important role in the recruitment process because any loss of potential applicants in the first step of the recruitment process can minimize the effectiveness of the selection system. Thus, investigating factors affecting organizational attractiveness of potential applicants will be helpful to attract extensive potential applicants in the war for talent. Moreover, the prior expatriate literature has shown that expatriate candidates who display more willingness to be dispatched are highly likely to accept foreign assignments and adapt well to uncertain and unfamiliar locations when compared to candidates who demonstrate less willingness (Peltokorpi \& Froese, 2014). Consequently, we conclude that it is one of the key factors for making potential expatriate applicants apply for international assignments. Therefore, we bring this concept into the expatriate context and modify it as subsidiary attractiveness. Specifically, we examine the attractiveness of Vietnam and the US subsidiaries to investigate how potential expatriate applicants are attracted to a certain subsidiary. As shown in Figure 1, we call the modified version of organizational attractiveness subsidiary attractiveness and examine how the host country image and cultural intelligence affect the subsidiary attractiveness.

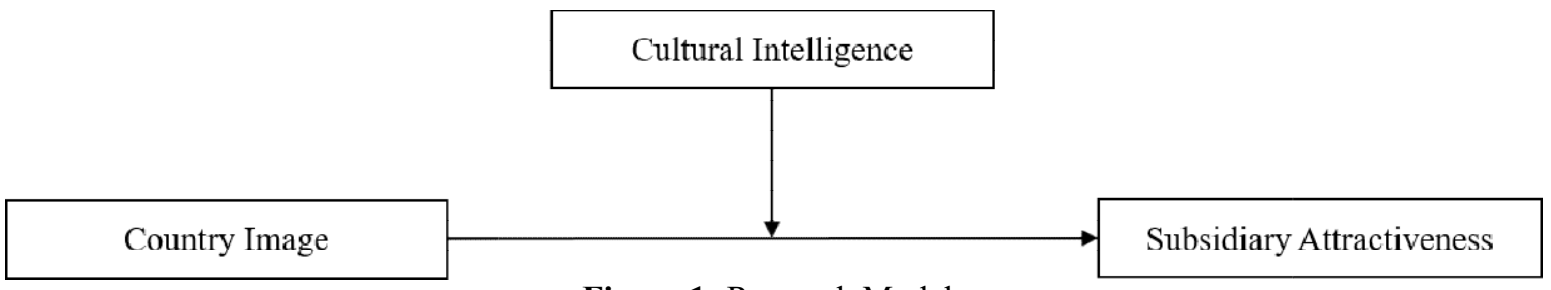

Figure 1: Research Model

\subsection{Hypotheses Development}

\subsubsection{Host Country Image}

Location concerns are one of the most common factors for expatriates that affect international mobility decisions (De Eccher \& Duarte, 2018; Dickmann, 2012; Kim \& Froese, 2012; Pinto et al., 2012). Due to the huge increase and internationalization of MNEs, the demand for expatriates in emerging market countries has surged dramatically (De Eccher \& Duarte, 2018). However, the existing literature has overlooked the reasons why certain host locations are more preferred than others (Hippler, 2009). Few study identifies that country image serves as one of the influential factors affecting expatriates' location choice (Hong \& Kim, 2019; Kim \& Froese, 2012).

Country image refers to the prejudices or stereotypes that individuals may hold toward a certain nation (Allred et al., 2000). Stereotypes are often created through the economical, technological, and political development of given countries (Martin \& Eroglu, 1993). In general, potential expatriate applicants do not have complete information about host locations, including working and living conditions, social infrastructures, the education system for their children, safety issues, cultural differences and so on (Hong \& Kim, 2019). According to the anxiety/uncertainty management theory, individuals feel anxiety and uncertainty when they encounter intercultural situations because they do not know how to properly communicate with people from different cultures (Black, 1988). Thus, the feelings of anxiety and uncertainty are highly likely to appear as expatriates are not fully aware of how to act and communicate properly with unfamiliar people in culturally different environments. Moreover, the level of uncertainty and anxiety arising from unfamiliar environments differs depending on the country to which expatriates are dispatched. That is, the country image, an extrinsic symbolic image, can largely affect the feelings of anxiety and uncertainty in expatriate candidates thus influencing the attractiveness of the host country. Therefore, it is possible that a potential expatriate may judge the attractiveness of a host location by its country image as they have 
insufficient objective information about the working and living conditions. Furthermore, the country image of developed countries will be more favorable than the image of emerging countries as it is created by economic, political, and technological development levels. For example, expatriate candidates may assume that working and living conditions of the assignment location in the developed countries will be safer and more comfortable than international assignments in emerging countries. Moreover, they assume that the infrastructure, living standards, the education systems for their children, and safety systems of developed countries will be more reliable than those of emerging countries. Consequently, the level of anxiety and uncertainty will not be increased significantly when potential expatriates are dispatched to developed countries compared to when they are sent to emerging ones. However, they may assume that host nations in emerging countries do not offer safe and comfortable working and living conditions. This assumption will make them overly cautious and more attuned to the feelings of anxiety and uncertainty about international assignments, thus reducing the attractiveness of the subsidiary in the emerging countries. Supporting our arguments, Froese et al. (2010) found that national and technological images of host countries affect the attraction of assignment destinations. Also, Hong \& Kim (2019) found that potential Korean expatriate candidates were more attracted to a US-based subsidiary than a Vietnam-based one. Based on this, we argue that:

H1: Compared to a Vietnam-based subsidiary, potential Korean expatriate candidates perceive that a US-based subsidiary is a more attractive destination for international mobility.

\subsection{Cultural Intelligence}

Increasing globalization creates challenges for MNEs managing inter-cultural interactions among culturally diverse employees. The ability to function effectively in diverse culture has been labeled cultural intelligence (Early \& Ang, 2003). Cultural intelligence (CQ), first introduced by Earley and Ang (2003) refers to a persons' capability to adapt to situations that are culturally different, and this concept has received a lot of attention in the globalized workplace (Malek \& Budhwar, 2013). The CQ concept consists of four dimensions: meta-cognitive, cognitive, motivational, and behavior CQ (Ang et al., 2007). Meta cognitive CQ refers to the mental capability to understand cultural knowledge. Cognitive CQ reflects a general knowledge of culture. Particularly, both CQ dimensions show how individuals have knowledge of other cultures and are aware of cultural differences. Motivational CQ indicates individual capability or willingness to learn about intercultural situations. Lastly, behavior CQ shows the capability to exhibit the proper actions, including verbal and nonverbal behavior, in inter-cultural situations. For example, people with high behavior CQ can display culturally appropriate tones, gestures, words, and face expressions (Ang et al., 2007). Consequently, individuals with high CQ have the capability to understand and act more suitably across various cultural circumstances (Thomas, 2006). Therefore, CQ is regarded as a unique explanatory factor in predicting intercultural effectiveness in human resource management literature. Particularly, CQ has been a decisive predictor of expatriate adjustment or performance in expatriate literature. For example, CQ has been related to expatriate outcomes such as cultural adaptation (Ward et al., 2008; Ang et al., 2007). Also, Malek and Budhwar (2013) found that the four dimensions of CQ are positively related to expatriate adjustment and performance among 134 expatriates based in MNEs in Malaysia.

Based on this, we argue that the CQ of potential expatriate candidates can be a potential moderator which may affect the perception of the host country image on the attractiveness of the host location. According to the AUM theory, individuals can exhibit anxiety and uncertainty when they face culturally different circumstances, as they do not know the appropriate way to communicate or act according to the culturally diverse situations (Black, 1988). Furthermore, such feelings can be significantly magnified when the host location is an emerging country in which they assume that working and living conditions will not be safe and comfortable when compared to a host location in a developed country. However, expatriate applicants with high CQ are more sensitive to intercultural interactions and they intuitively know how to behave and act exactly in order to facilitate cross-cultural situations. Expatriate applicants with a high CQ will generally be attracted to global organizations with international backgrounds, have higher cooperative motives with foreigners, and be able to devote more effort to overcome cross-cultural barriers. Such soft skills will be more helpful for locations that are assumed to be uncomfortable and not safe, such as emerging countries. Based on the above argument, we argue that:

H2: Cultural intelligence (CQ) of Korean expatriate candidates positively moderates the host country image and subsidiary attractiveness in that, the higher the level of cultural intelligence of Korean candidates, the stronger the positive effect of the Vietnam-subsidiary on subsidiary attractiveness when compared to the US. 


\section{Methodology}

\subsection{Sample}

To explore the impacts of host locations and cultural intelligence on the organizational attractiveness of expatriate subsidiaries, Korean full-time workers were approached to participate in the study. In total, 445 full-time workers took part in the study considering expatriation destinations (Vietnam vs. the US) and individual CQ. Their average age was 41 years $(\mathrm{SD}=8.00)$, and $52.4 \%(\mathrm{n}=233)$ were male. The profiles of the sample are shown in Table 1.

Table 1: Sample Characteristics

\begin{tabular}{|c|c|c|c|c|c|}
\hline Age (years) & Number & $\%$ & Working experience (years) & Number & $\%$ \\
\hline $25-34$ & 99 & 22.25 & Below 1 & 27 & 6.07 \\
\hline $35-44$ & 211 & 47.42 & $1-4$ & 66 & 14.83 \\
\hline $45-54$ & 105 & 23.59 & $5-10$ & 128 & 28.76 \\
\hline $55-64$ & 30 & 6.74 & Over 10 & 224 & 50.34 \\
\hline
\end{tabular}

\subsection{Procedures}

Participants responded through a Qualtrics online survey that randomly showed one of two conditions for a potential expatriate location (Vietnam-based or US-based). Each participant was given a packet containing instructions and an individual information survey. Respondents were asked to imagine themselves as expatriate candidates for a certain subsidiary's location. The participants were asked to answer a series of questions on the organizational attractiveness of the subsidiaries from the perspective of an expatriate candidate and a series of questions on individual CQ.

Table 2: Measurement Model Results

\begin{tabular}{|l|c|c|}
\hline \multicolumn{1}{|c|}{ Measurement items } & $\begin{array}{c}\text { Factor } \\
\text { loading }\end{array}$ & Cronbach's $\alpha$ \\
\hline Cultural intelligence & & 0.837 \\
\hline I enjoy interacting with people from different cultures. & 0.866 & \\
\hline I am confident that I can socialize with locals in a culture that is unfamiliar to me. & 0.899 & \\
\hline I am sure I can deal with the stresses of adjusting to a culture that is new to me. & 0.838 & \\
\hline Organizational attractiveness & & 0.933 \\
\hline I would exert a great deal of effort to work for this subsidiary. & 0.931 & \\
\hline I would choose this subsidiary as the top choice for an expatriate. & 0.941 & \\
\hline I would like to work for this subsidiary. & 0.945 & \\
\hline
\end{tabular}

\subsection{Measures}

This study adapted Ang et al.'s (2007) scale capturing motivational CQ, which predicts individual ability on adjustment of global professionals, beyond realistic living and job conditions. Three items for CQ were measured with a 7-point Likert-scale, which ranged from $1=$ 'strongly disagree' to $7=$ 'strongly agree.' As shown in Table 2, Cronbach's alpha of CQ is 0.837 and the factor loadings appear from 0.838 to 0.899 . Organizational attractiveness, 
which was to assess the respondent's willingness to expatriate, was measured using three items based on Turban's (2001) study. The scale on the willingness to accept expatriation ranged from $1=$ 'not at all willing' to $7=$ 'very much willing.' Cronbach's alpha for the subsidiary attractiveness was 0.933 and factor loadings appear from 0.931 to 0.945 . Construct-level correlation coefficients between these focal variables and descriptive statistics are summarized in Table 3.

Table 3: Descriptive Statistics and Correlations

\begin{tabular}{|l|c|c|c|c|}
\hline & Mean & S.D. & 1 & 2 \\
\hline 1. Host-locations $^{*}$ & 0.488 & 0.500 & & \\
\hline 2. Cultural intelligence & 4.149 & 0.747 & 0.002 & \\
\hline 3. Organizational attractiveness & 4.220 & 1.123 & -0.172 & 0.212 \\
\hline
\end{tabular}

* 0 = an US-based subsidiary; 1 = a Vietnam-based subsidiary

\section{Results}

To confirm the hypotheses, this study conducted a two-way ANOVA test that included the main effects of host locations and CQ on the organizational attractiveness of expatriate subsidiaries as well as the effect of the interaction between subsidiary's locations and CQ. Table 4 shows that host locations had a significant direct effect on organizational attractiveness $\left(F(1,441)=110504, p<0.005, \eta_{p}{ }^{2}=0.025\right)$. This result reveals that Korean expatriate candidates perceive that a Vietnam-based subsidiary $(\mathrm{M}=4.02, \mathrm{SD}=1.175)$ is a less attractive destination for an international assignment compared to a US-based subsidiary $(\mathrm{M}=4.41, \mathrm{SD}=1.040)$. Thus, Hypothesis 1 was supported.

Table 4: Results of the Two-way ANOVA for organizational attractiveness

\begin{tabular}{|c|c|c|c|c|c|}
\hline & $D f$ & MS & $F$-value & $P$-value & Partial $\eta^{2}$ \\
\hline Host locations & 1 & 13.405 & 11.504 & 0.001 & 0.025 \\
\hline Cultural intelligence & 1 & 20.136 & 17.281 & 0.000 & 0.038 \\
\hline Host locations x Cultural intelligence & 1 & 10.147 & 8.709 & 0.003 & 0.019 \\
\hline Error & 441 & 1.165 & & & \\
\hline
\end{tabular}

As shown in Table 4, the effect of the interaction between host locations and CQ on the organizational attractiveness of an expatriate destination was significant $\left(F(1,441)=10.147, p<0.005, \eta_{p}{ }^{2}=0.019\right)$. Additionally, as shown in Table 6, planned contrasts revealed that Korean expatriate candidates are more attracted to a Vietnambased subsidiary $(F(1,441)=24.807, p<0.001)$ when cultural intelligence is high $(\mathrm{M}=4.44, \mathrm{SD}=1.091)$ than when $\mathrm{CQ}$ is low $(\mathrm{M}=3.70, \mathrm{SD}=1.141)$. However, Korean workers' intentions did not differ significantly across high $\mathrm{CQ}(\mathrm{M}=4.48, \mathrm{SD}=1.278)$ and low $\mathrm{CQ}(\mathrm{M}=4.36, \mathrm{SD}=0.830)$ when the US was the expatriate location $(F(1$, $441)=0.741, p>0.10)$. These results supported Hypothesis 2. That is, the positive moderating effect of cultural intelligence on the relationship between the host location and the organizational attractiveness of a foreign subsidiary to Korean expatriate candidates is stronger when Vietnam rather than the US is the assignment location.

Table 5: Results of planned contrasts for organizational attractiveness

\begin{tabular}{|c|c|c|c|c|c|}
\hline & & $d f$ & SS & $F$-value & $P$-value \\
\hline \multirow{2}{*}{ High vs. Low CQ } & Vietnam & 1 & 28.901 & 24.807 & 0.000 \\
\cline { 2 - 6 } & The US & 1 & 0.863 & 0.741 & 0.390 \\
\hline
\end{tabular}


Figure 1 illustrates the simple effect of cultural intelligence. The difference between high CQ and low CQ was significant only for Korean expatriate candidates considering Vietnam as an expatriate location. In this condition they tended to be more attracted to a Vietnam-based subsidiary with a higher level of CQ than to a subsidiary with a lower level of CQ. However, for Korean workers considering the US as an expatriate destination, the mean of organizational attractiveness with a high CQ does not significantly differ from that with a low CQ. Based on these results, employees' CQ may be a key factor influencing the organizational attractiveness of expatriate subsidiaries, particularly when the assignment location is a less favorable country.
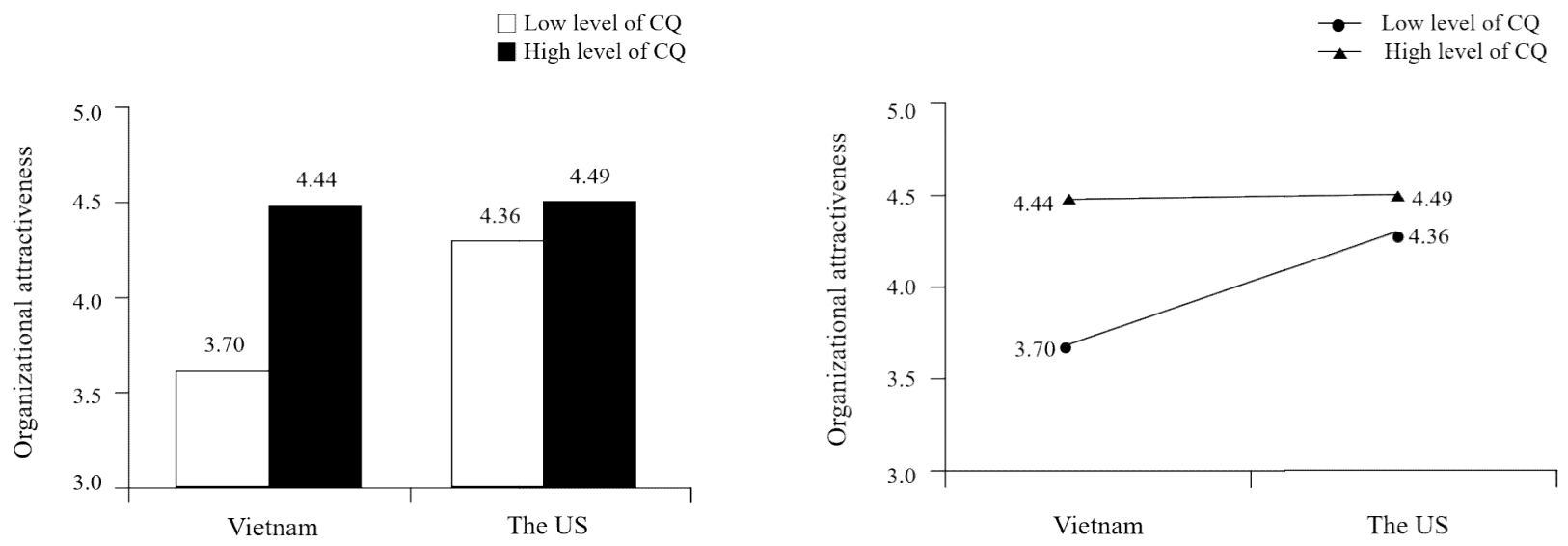

Figure 2: The effects of host-locations and cultural intelligence on organizational attractiveness

\section{Discussion}

\subsection{Managerial and Academic Implications}

This study provides new insights that enrich the expatriate literature and generates implications that may help manage expatriates successfully. First of all, based on AUM theory, this study examined the effect of the host country image and employees' CQ on a subsidiary's attractiveness. This theory has been adopted in the recruitment literature to explain the effects of a country image or corporate image on job choice decisions of potential applicants. However, it has not often been applied to explain the subsidiary attractiveness to expatriate candidates in the expatriate literature. Transferring the AUM theory to the expatriate literature, this study enriches the understanding of how organizations attract potential expatriate applicants to certain host locations. Specifically, expatriates might face unfamiliar conditions and diverse uncertainty which they have not previously encountered in their home county. Thus, they need to consider how to handle such anxiety and uncertainty in a foreign country assigned as a subsidiary. In this situation, potential expatriates use information such as the country image to judge the attractiveness of the host location as an expatriate destination. Compared to the favorable country image of developed countries, people may have stereotypes or prejudices to evaluate emerging countries as less favorable locations which have lower levels of economic, political, and technological developments. These stereotypes or prejudices affect the level of anxiety and uncertainty and potential expatiates are less attractive to unfavorable local conditions.

Second, this study suggested the role of employees' CQ to attract expatriate candidates in a foreign subsidiary which has a less favorable country image. As the capability to direct and sustain energy toward learning about and functioning in situations characterized by cultural differences, CQ might help potential expatriates reduce their anxiety and uncertainty. Through confidence in their cross-cultural effectiveness and attention toward cross-cultural situations based on an intrinsic interest, expatriate applicants perceive a lower level of anxiety and uncertainty toward working and living in unfamiliar environmental conditions, and they apply for expatriate positions with less emotional barriers toward foreign subsidiaries located in less favorable countries. Following such logic, this study found that the effect of CQ was more relevant for the Vietnam-based subsidiary than for the US-based subsidiary in increasing the effect of the host country's image on organizational attractiveness. Thus, by considering employees' 
CQ to mitigate challenges in attracting high-quality expatriate candidates to less favorable countries, this study significantly contributes to the expatriate literature.

Finally, this study showed that perceptions of host locations may affect subsidiary's attractiveness to expatriate candidates differently. Expatriate candidates are more willing to work and live in a more favorable country, such as the US, since they expect a better economic, political, and social environment in developed countries. Thus they may assume that they can enjoy better living and working conditions compared to those found in less developed countries. Proving information on the positive and valuable conditions of expatriate locations is important for attracting prospective expatriates to less favorable locations. Moreover, CQ helps to attract potential expatriates by reducing uncertainties and confusion of behaviors surrounding expatriates. Potential expatriates who have a higher level of CQ may have lower emotional barriers toward living and working in less favorable environments. Moreover, they can better understand differences between home and host countries and adjust to unfamiliar conditions with less anxiety and uncertainty more easily. The international human resource department needs to build systematic process for enhancing individual CQ and develop elaborates program to manage employees' cultural intelligence.

\subsection{Limitations and Directions for Further Research}

This study has several limitations which suggest the need for future improvement. First, this study emphasizes the importance of employees' cultural intelligence to attract talented expatriates to emerging countries which have a less favorable country image. To compare the different effects of a country image, respondents were randomly shown one of two conditions (Vietnam-based or US-based) for a potential expatriate location and then asked their willingness to expatriate to the given location. However, this study did not contain individual preference or familiarity with the country. Moreover, individual characteristics (such as ethnocentrism, global orientation, or work value) and other personal considerations (age, family, or work experience) could affect the likelihood of accepting a role of an expatriate in a certain county. Further study needs to consider these potential variables and build a comprehensive research model to confirm the effect of country image as well as the role of individual CQ. In addition, this study conducted a two-way ANOVA to compare two different groups shown one expatriate destination. Future studies could collect survey data, including a willingness to expatriate in two different countries, from each respondent simultaneously and conduct a hierarchical regression including several control variables.

Second, this study demonstrated the importance of country image and cultural intelligence for attracting potential expatriates to foreign assignments. However, examining the roles of these variables on expatriates' performance during foreign assignments might be valuable for firms' survival because relocation to a foreign country involves several changes and challenges, including adapting to a different culture, establishing a new social network, and learning a foreign language. Thus, such challenges might affect the expatriate performance of expatiates in foreign subsidiaries and could influence them in achieving better performance across the organization. Thus, it would be worthwhile exploring the roles of the host country image and CQ on expatriate performance.

Finally, this study confirmed the moderating effect of cultural intelligence by focusing on motivational intelligence. Motivational intelligence refers to the mental capacity which helps deal with a particular task or situation more successfully. Motivational capabilities are considered a critical means of problem solving. To handle unfamiliar conditions in foreign countries and several challenges in an expatriate destination, motivational intelligence is likely essential to adjust to a local environment and achieve organizational performance in line with the domestic conditions. However, according to Ang et al.'s (2007) study, CQ has a multidimensional construct, such as metacognitive, cognitive, motivational, and behavioral intelligence. Metacognitive intelligence refers to the processes of controlling cognition to acquire and understand knowledge, and cognitive intelligence refers to knowledge structures as part of the intellect. On the other hand, behavioral intelligence refers to overt actions or outward manifestations related to what individuals do rather than what they think. These four dimensions of CO are different facets of the overall capability to manage and function effectively in various cultural settings. Further study might conduct a multidimensional approach to confirm the role of CQ on the relationship between country image and subsidiary attractiveness and find different effects of cultural intelligence scales respectively. 


\section{References}

Ang, S., Van Dyne, L., Koh, C., Ng, K. Y., Templer, K. J., Tay, C., \& Chandrasekar, N. A. (2007). Cultural intelligence: its measurement and effects on cultural judgment and decision making, cultural adaptation and task performance. Management and Organization Review, 3(3), 335-371.

Baum, M., \& Kabst, R. (2013). How to attract applicants in the Atlantic versus the Asia-Pacific region? a crossnational analysis on China, India, Germany, and Hungary. Journal of World Business, 48(2), 175-185.

Black, J. S. (1988). Work role transitions: A study of American expatriate managers in Japan. Journal of International Business Studies, 19(2), 277-294.

Brewster, C., Bonache, J., Cerdin, J. L., \& Suutari, V. (2014). Exploring expatriate outcomes. International Journal of Human Resource Management, 25(4), 1921-1937.

Caligiuri, P. M. (2000). Selecting expatriates for personality characteristics: A moderating effect of personality on the relationship between host national contact and cross-cultural adjustment. Management International Review, 40(1), 61-80.

de Eccher, U., \& Duarte, H. (2018). How images about emerging economies influence the willingness to accept expatriate assignments. The International Journal of Human Resource Management, 29(4), 637-663.

Dickmann, M. (2012). Why do they come to London? Exploring the motivations of expatriates to work in the British capital. Journal of Management Development, 31(8), 783-800.

Dupuis, M. J., Haines, V. Y. III., \& Saba, T. (2008). Gender, family ties, and international mobility: cultural distance matters. International Journal of Human Resource Management, 19(2), 274-295.

Earley, P. C. (2002). Redefining interactions across culture and organizations: moving forward with cultural intelligence. Research on Organizational Behavior, 24(1), 271-299.

Earley, P. C., \& Ang, S., (2003). Cultural intelligence: Individual interactions across cultures. Academy of Management Review, 31(2), 489-493.

Froese, F., \& Garrett, T. (2010). Organizational attractiveness of foreign-based companies: a country of origin perspective. International Journal of Self-Assessment, 18(3), 271-289.

GMT (2016). Global Mobility Trends Survey Report. Retrieved February 30, 2020, from http://globalmobilitytrends.bgrs.com.

Harvey, M., \& Moeller, M. (2009). Expatriate mangers: a historical review. International Journal of Management Reviews, 11(3), 275-296.

Hippler, T. (2009). Why do they go? Empirical evidence of employees' motives for seeking or accepting relocation. The International Journal of Human Resource Management, 20(6), 1381-1401.

Hong, G. H., \& Kim, E. M. (2019). How to attract talented expatriates: the key role of sustainable HRM. Sustainability, 11(19), 5373.

Kim, J., \& Froese, F. J. (2012). Expatriation willingness in Asia: the importance of host-country characteristics and employees' role commitments. The International Journal of Human Resource Management, 23(16), 3414-3433.

Lieven, F., Van Hoye, G., \& Schreur, B. (2005). Examining the relationship between employer knowledge dimensions and organizational attractiveness: an application in a military context. Journal of Occupational \& Organizational Psychology, 78(4), 553-573.

Malek, M. A., \& Budhwar, P. (2013). Cultural intelligence as a predictor of expatriate adjustment and performance in Malaysia. Journal of World Business, 48(2), 222-231.

Martin, I. M., \& Eroglu, S. (1993). Measuring a multi-dimensional construct: country image. Journal of Business Research, 28(3), 191-210.

Peltokorpi, V., \& Froese, F. (2014). Expatriate personality and cultural fit: the moderating role of host country context on job satisfaction. International Business Review, 23(1), 293-302.

Pinto, L. H., Cabral-Cardoso, C., \& Werther Jr, W. B. (2012). Compelled to go abroad? motives and outcomes of international assignments. The International Journal of Human Resource Management, 23(11), 2295-2314.

Pomeroy, A. (2006). Pacific rim most challenging for expatriates. HR Magazine, 51(11), 14.

Shaffer, M. A., Kraimer, M. L., Chen, Y. P., \& Bolino, M. C. (2012). Choices, challenges, and career consequences of global work experiences: a review and future agenda. Journal of Management, 38(4), 1282-1327.

Thomas, D. C., Elron, E., Stahl, G., Ekelund, B. Z., Ravlin, E. C., Cerdin, J. L., \& Maznevski, M. (2008). Cultural intelligence: domain and assessment. International Journal of Cross-Cultural Management, 8(2), 123-143.

Turban, D. B. (2001). Organizational attractiveness as an employer on college campuses: an examination of the applicant population. Journal of Vocational Behavior, 58(2), 293-312. 
Turban, D. B., Forret, M. L., \& Hendrickson, C. L. (1998). Applicant attraction to firms: influences of organization reputation, job and organizational attributes, and recruiter behaviors. Journal of Vocational Behavior, 52(1), 2444.

Van Hoye, G., \& Saks, A. M. (2011). The instrumental-symbolic framework: Organizational image and attractiveness of potential applicants and their companions at a job fair. Applied Psychology, 60(2), 311-335.

Ward, C., Fischer, R., Lam, F. S. Z., \& Hall, L. (2008). The convergent, discriminant, and incremental validity of scores on a self-report measure of cultural intelligence. Educational and Psychological Measurement, 20(1), 121. 